\title{
PHONOCARDIOGRAPHY-BASED MITRAL VALVE PROLAPSE DETECTION USING AN ARTIFICIAL NEURAL NETWORK
}

\author{
Vesna Bogdanovic ${ }^{1}$, Ivan Bozic ${ }^{2}$, Ana Gavrovska ${ }^{3}$, Vladislava Stojic ${ }^{4}$, Vladimir Jakovljevic ${ }^{5}$ \\ "Zvezdara" Health Centre, Belgrade, Serbia \\ ${ }^{2}$ School of Electrical Engineering, University of Belgrade (Department of Telecommunications) \\ ${ }^{3}$ Center of the School of Electrical Engineering, University of Belgrade \\ ${ }^{4}$ Faculty of Economics, University of Kragujevac, Serbia \\ ${ }^{5}$ Department of Physiology, Faculty of Medical Sciences, University of Kragujevac, Serbia
}

\section{FONOKARDIOGRAFSKA DETEICIJA PROLAPSA MITRALNE VALVULE \\ UPOTREBOM ARTEFICIJALNE NEURONSKE MREŽE \\ Vesna Bogdanović ${ }^{1}$, Ivan Božić ${ }^{2}$, Ana Gavrovska ${ }^{3}$, Vladislava Stojić ${ }^{4}$, Vladimir Jakovljević ${ }^{5}$ \\ ${ }^{1}$ Kliničko-bolnički centar “Zvezdara”, Beograd, Srbija \\ ${ }^{2}$ Katedra za telekomunikacije, Elektrotehnički fakultet, Univerzitet u Beogradu, Srbija \\ 3Inovacioni centar Elektrotehničkog fakulteta, Univerzitet u Beogradu, Srbija \\ ${ }^{4}$ Ekonomski fakultet, Univerzitet u Kragujevcu, Srbija \\ ${ }^{5}$ Katedra za fiziologiju, Fakultet medicinskih nauka, Univerzitet u Kragujevcu, Srbija}

Received / Primljen: 09.09.2013.

Accepted / Prihvaćen: 25.09.2013.

\begin{abstract}
Mitral valve prolapse (MVP) is the most common valve anomaly and the most frequent cause of isolated mitral insufficiency. MVP has a mostly benign course and prognosis in childhood; however, complications, such as severe mitral regurgitation, infectious endocarditis, pulmonary embolism, arrhythmia and sudden death, occur more often in elderly people, demonstrating the need for prompt diagnostics and prevention. Due to itsfrequent occurrence, failures in diagnosing $M V P$ and the clinical importance of early MVP detection, the aim of this study was to develop an original, non-invasive and easily applicable diagnostic method for MVP detection in children and adolescents by using an artificial neural network (ANN). Cardiac sounds were recorded by auscultation using electronic stethoscope in 48 children with MVP, 49 healthy children and 38 children with a pathological heart murmur from atrial septal defect (ASD), ventricular septal defect (VSD), ductus arteriosus persistence (DAP), aortic stenosis (AS), pulmonic stenosis (PS), aortic coarctation (ACo), mitral regurgitation (MR), mitral insufficiency (MI) and tricuspid insufficiency (TII. In electronic stethoscopes, the sound is archived in the internal memory of the stethoscope and then transmitted to a computer by a transmitter. Basic software for the check-up and sound analysis is provided along with the electronic stethoscopes and provides a phonocardiograph and spectral presentation of auscultative findings. For further qualitative analysis, the digital form (format ". e4k) of the phonocardiogram is transformed into standard ".wav format, which is the first step in the processing of the digital signal for studying and testing with an ANN. The obtained precision of MVP classification category was $71.2 \%$. These results may be interesting for the phonocardiograph diagnosis of MVP in children and adolescents.
\end{abstract}

Keywords: phonocardiography - mitral valve prolapse -neural network

\section{SAŽETAK}

Prolaps mitralne valvule (MVP) je najčešća anomalija zalistaka i najčešći uzrok izolovane mitralne insuficijencije. MVP ima najpovoljniji tok i prognozu u detinjstvu, dok komplikacije kao što su teška mitralna regurgitacija, infektivni miokarditis, embolija pluća, aritmija i iznenadna smrt se češće javljaju kod starijih ljudi, što zahteva brzu dijagnostiku $i$ prevenciju. Usled učestalog javljanja, otežane dijagnostike $i$ kliničkog značaja ranog otkrivanja MVP, cilj ove studije je bio da razvije originalni, neinvazivni i lako primenljiv dijagnostički metod za otkrivanje MVP kod dece i adolescenata upotrebom arteficijalne neuronske mreže (ANN). Srčani tonovi kod 48 dece sa MVP, 49 zdrave dece $i 38$ dece sa patološkim srčanim šumovima nastalim usled atrijalnog septalnog defekta (ASD), ventrikularnog septalnog defekta (VSD), duktus arteriosus persistensaotvorenog arterijskog kanala (DAP), aortne stenoze (AS), stenoze plućne arterije (PS), koarktacije aorte $(A C o)$, mitralne regurgitacije (MR), mitralne insuficijencije (MI) $i$ trikuspidalne insuficijencije (TI) su zabeleženi auskultacijom upotrebom elektronskimog stetoskopopa. U elekctronskom stetoskopu zvuk se snima na unutrašnjoj memoriji stetoskopa a potom pomoću transmitera prenosi na memoriju kompjutera. Osnovni softver za proveru i analizu zvuka se nalazi u sklopu elektronskog stetoskopa i omogućava fonokardiografsku i spektralnu prezentaciju auskultatornog nalaza. U daljoj kvalitativnoj analizi, fonokardiogram u digitalnom obliku (format ". e4k) se prevodi u standard". wav format, koji je prvi korak u obradi digitalnog signala, proučavanju i testiranju ANN. Dobijena preciznost svrstavanja MVP u odgovarajuću kategoriju je bila $71.2 \%$. Ovi rezultati mogu biti interesantni u fonokardiografskoj dijagnostici MVP kod dece i adolescenata.

Ključne reči: fonokardiografija, prolaps mitralne valvule, neuronska mreža 
ABBREVIATIONS:

\author{
ANN - artificial neural network \\ AS - aortic stenosis \\ ASD - atrial septal defect \\ ACo - aortic coarctation \\ DAP - ductus arteriosus persistence \\ FN - false negatives \\ FP - false positives \\ LSSVM - Least Square Support \\ Vector Machine
}

MI - mitral insufficiency

MLP - multilayer perceptron

MR - mitral regurgitation

PS - pulmonic stenosis

MVP - mitral valve prolapse

TI - tricuspid insufficiency

TN - true negatives

TP - true positives

VSD - ventricular septal defect

\section{INTRODUCTION}

Mitral valve prolapse (MVP) is a pathological dislocation of the front or back segment or both mitral valves during systole through the plane of the mitral annulus into the area of the left atrium (1). MVP is the most frequent valve anomaly and is the most frequent cause of isolated mitral insufficiency (2). A characteristic auscultator finding is a meso-systolic click and late systolic murmur. MVP mostly has a benign course and a good prognosis in childhood; however, complications, such as severe mitral regurgitation, infectious endocarditis, pulmonary embolism, arrhythmia and sudden death, more often occur with elderly people, demonstrating the need for prompt diagnostics and prevention to preserve the structural and functional integrity of the myocardium. The true prevalence of mitral valve prolapse is not known due to the variety of research techniques and diagnostic criteria. The prevalence varies from a very low $0.4 \%$ to a very high $35 \%$, depending on sex and age. The characterisation of heart acoustic signals by auscultation and the establishment of a diagnosis depend on the skill and individual experience of a doctor rather than just his/her theoretical knowledge (3-7). The utilisation of an electronic stethoscope and special computer program can provide a reliable diagnosis and thereby significantly reduce the number of patients who are sent for echocardiography. Considering the frequency of occurrence, failures in diagnostics and clinical importance of early MVP detection, the aim of this study was to develop an original, non-evasive and easily applicable diagnostic method for the early identification of MVP in children and adolescents by using an artificial neural network (ANN)

An artificial neural network (ANN) is a biologically inspired computational model that processes artificial nodes (neurons) and the connections between these processing elements and their parameters $(8,9)$. The strength of these connections is characterised by weights. Generally, ANNs are meant to be useful models for humanlike problem solving and knowledge engineering. ANNs are widely used for pattern classification and nonlinear adaptive filtering. In this paper, specific medical patterns can be treated using an ANN-based approach for a classification task.

\section{PATIENTS AND METHODS}

\section{Subjects}

In the period from 2010-2012, 2019 7- to 19-year-old school children received a general check-up at Health Centre "Zvezdara". Auscultation was performed using an electronic stethoscope (3M Littmann 4100WS). Children with characteristic findings of a meso-systolic click or meso-systolic click and late systolic murmur; healthy children who were engaged in sports and in whom auscultation revealed no murmurs or only a harmless, Still's murmur; and children with a pathological murmur from an atrial septal defect (ASD), ventricular septal defect (VSD), ductus arteriosus persistence (DAP), aortic stenosis (AS), pulmonic stenosis (PS), coarctation of aorta (ACo), mitral regurgitation (MR), mitral insufficiency (MI) or and tricuspid insufficiency (TI) were sent to University Children's Clinic Belgrade for echocardiograph confirmation of the diagnosis using a sonography apparatus, the Diasonics imager 100 and Aloka-Echo Camera-SDD-680 probes of 355 i 5 $\mathrm{MHz}$. Children with a previously identified diagnosis were also included in the research. For this study, the examinees were divided into three groups:

1. MVP - 48 examinees with mitral valve prolapse

2. HEALTHY - 49 examinees without a murmur or with a harmless Still's murmur

3. OTHERS - 38 examinees with ASD, VSD, DAP, AS, PS, CA, MR, MI, or and TI

\section{Recordings}

The use of an electronic stethoscope, the data collection and processing and the corresponding phonocardiograph recordings were approved by the Ethical Committee of Health Centre "Zvezdara" in Belgrade.

Auscultation using an electronic stethoscope and recordings of heart action is performed in a sitting position, i.e., in standard conditions, when the murmur intensity is greatest. To obtain a good quality recording, the stethoscope is adjusted for the sex, age, physical strength and mass and osteomuscular structure. For each examinee, there were at least three sound recordings lasting 8-10 seconds and the best recording was selected for digital signal 
analysis. The sound was converted into a digital signal in the electronic stethoscope, archived in the internal memory of the stethoscope and then transmitted and archived in a computer (Latitude E6400, 2.40 GHz, 4.0 GB, IC for the transmission of data from the stethoscope). Basic software (3M Littmann software for sound analysis V2.0) for the examination and analysis of sounds is provided along with the electronic stethoscope and provides phonocardiography and spectral analysis of auscultative recordings. All results and data are archived in one database, which contains phonocardiograph recordings in digital form (format *. e4k), which is combined with medical information in an e-card and an echocardiograph examination of the patient. For further quality analysis, the recording should be transformed into standard *.wav format, which is the first step in the digital processing of the signal.

\section{Artificial Neural Network (ANN)}

A main advantage of an ANN is the opportunity to perform nonlinear analysis. Second, due to its architecture, ANN will not malfunction when an element of the ANN fails. In addition, ANNs do not require reprogramming when new elements are encountered; instead, their behaviour will adapt to a new environment. This is known as learning or ANN training.

Figure 1 shows a basic structural element of an ANN. Each neuron consists of two parts: the net function and the activation function. The net function determines how the network inputs are combined inside the neuron. In contrast, the activation function represents a linear or nonlinear transformation, which determines the output of each neuron.

Back-propagation is a common method of training artificial neural networks. From a target value, network is trained for a set of inputs. This method is a supervised learning method and represents a generalisation of the delta rule. Back-propagation requires a dataset of the desired outputs for many inputs to form the training set and it is the most useful feed-forward network (networks that have no feedback) algorithm. Back-propagation requires that the activation function is differentiable.
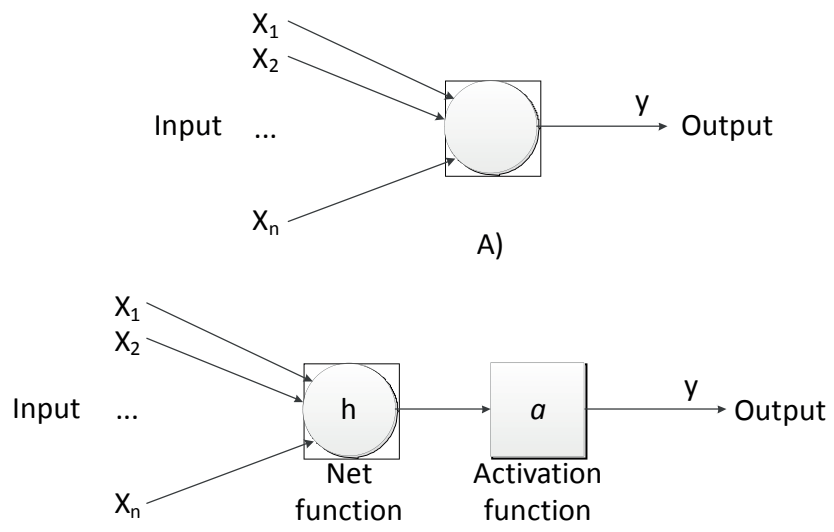

B)

Figure 1. Basic structure of an ANN: a) neuron; b) neuron modelled via the net, and activation functions

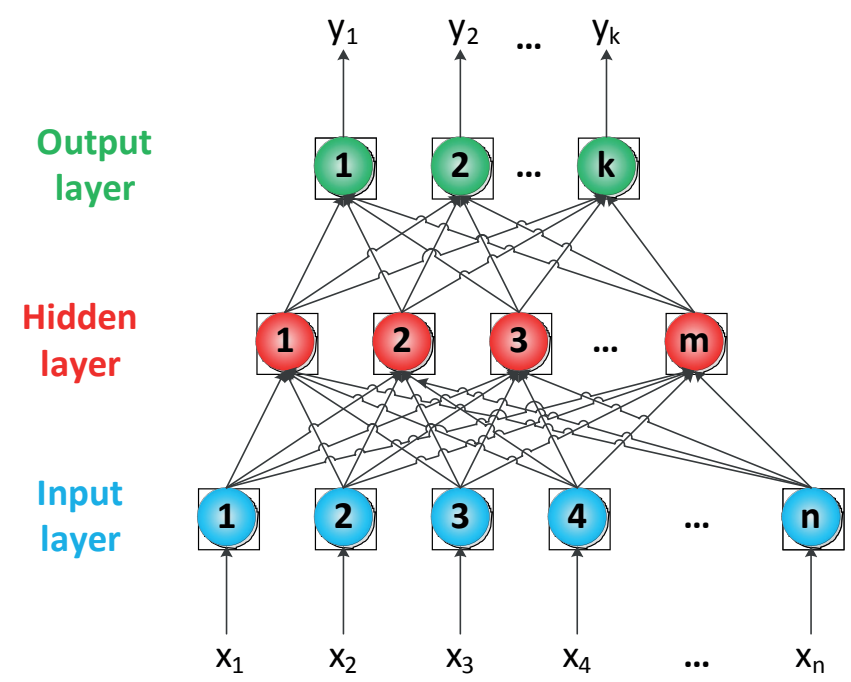

Figure 2. Multilayer Perceptron (MLP) model

A multilayer perceptron (MLP) neural network model consists of a feed-forward, layered network of neurons. Each neuron in an MLP has a nonlinear activation function that is continuously differentiable. Some of the most frequently used activation functions for MLP include the sigmoid function and the hyperbolic tangent function. A typical MLP configuration is depicted in Figure 2. Neurons are organised in three layers: input layer, hidden layer and output layer. The term "hidden" indicates that the output of these neurons will be fed into upper layer neurons and therefore hidden from the user, who only observes the output of output layer neurons. The MLP model is not permitted to create loops between neurons. An MLP provides a nonlinear mapping between its input and output.

An input matrix is created from all PCG recordings. Each PCG record is represented as a column vector in the input matrix; thus, the number of columns in the input matrix is equal to number of PCG recordings. The elements of these column vectors represent the samples of a particular PCG signal.

Input phonocardiograms are automatically classified into one of three possible classes (healthy, MVP, others neither healthy nor MVP). The MLP network and backpropagation method are used for supervised learning. The net function is a weighted linear combination:

$h_{w}=w_{0}+\sum_{j=1}^{N} w_{j} x_{j}$

where $w_{0}$ is the bias level (threshold), $w_{j}$ is the synaptic weight for $j$-th neuron input, $x_{j}$ is the $j$-th neuron input and $N$ is the number of inputs for each neuron. A sigmoid function is used as the activation function:

$a(h)=\frac{1}{1+e^{-h(w)}}$

This function is shown in Figure 3 . 


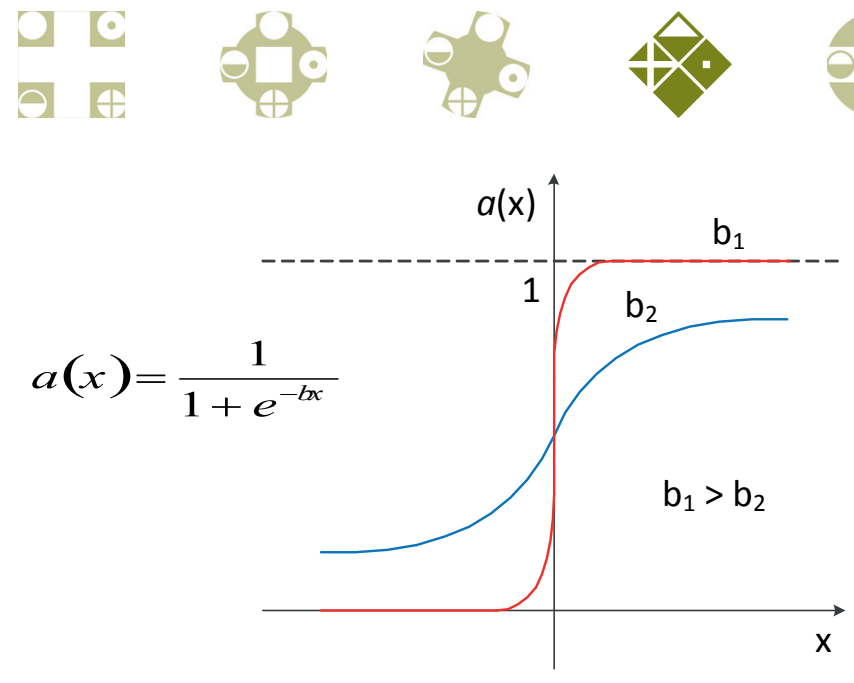

Figure 3. Sigmoid logistical activation function

For learning, we chose a logistic regression cost function because our classification problem results in a discrete set of possible values. Regularisation is used to prevent overfitting and underfitting situations. The regularisation parameter lambda is useful for controlling the regularisation process. Lambda must be chosen smartly because an incorrect lambda could decrease the accuracy of the prediction result . The cost function is represented as follows:

$$
J(w)=\frac{1}{N} \sum_{i=1}^{N}\left[-y^{(i)} \log \left(h_{w}\left(x^{(i)}\right)\right)-\left(1-y^{(i)}\right) \log \left(1-h_{w}\left(x^{(i)}\right)\right)\right]+\frac{\lambda}{2 N} \sum_{j=1}^{n} w_{j}^{2}
$$

where is $y(i)$ is the input set label, $x(i)$ are the input signals, $N$ is the number of training examplesand and $n$ is the number of neurons in the input layer. The back-propagation method uses online, batch, or stochastic learning. The batch gradient descent algorithm is implemented in the proposed solution. Gradient descent is a first-order optimisation algorithm. Negative gradient values are favoured for finding a local minimum of a function using gradient descent. The batch algorithm keeps the system weights constant while computing the error that is associated with each sample in the input. This method consumes more memory but requires fewer weight updates than the other two methods. In addition, batch learning yields a much more stable descent to local minima. The gradients of the cost function are as follows:

$$
\begin{array}{ll}
\frac{\partial J(w)}{\partial w_{0}}=\frac{1}{N} \sum_{i=1}^{N}\left(h_{w}\left(x^{(i)}\right)-y^{(i)}\right) x_{j}^{(i)} & \text { for } j=0 \\
\frac{\partial J(w)}{\partial w_{j}}=\left(\frac{1}{N} \sum_{i=1}^{N}\left(h_{w}\left(x^{(i)}\right)-y^{(i)}\right) x_{j}^{(i)}\right)+\frac{\lambda}{N} w_{j} & \text { for } j \geq 1
\end{array}
$$

Optimisation can minimise a continuous differentiable multivariate function. The Polack-Ribiere flavour of conjugate gradients is used to compute search direction. A line search using quadratic and cubic polynomial approximations and the Wolfe-Powell stopping criteria together with the slope ratio method are used to guess the initial step sizes. Additionally, several checks are performed to verify that the exploration is taking place and that the extrapolation will not be unboundedly large.
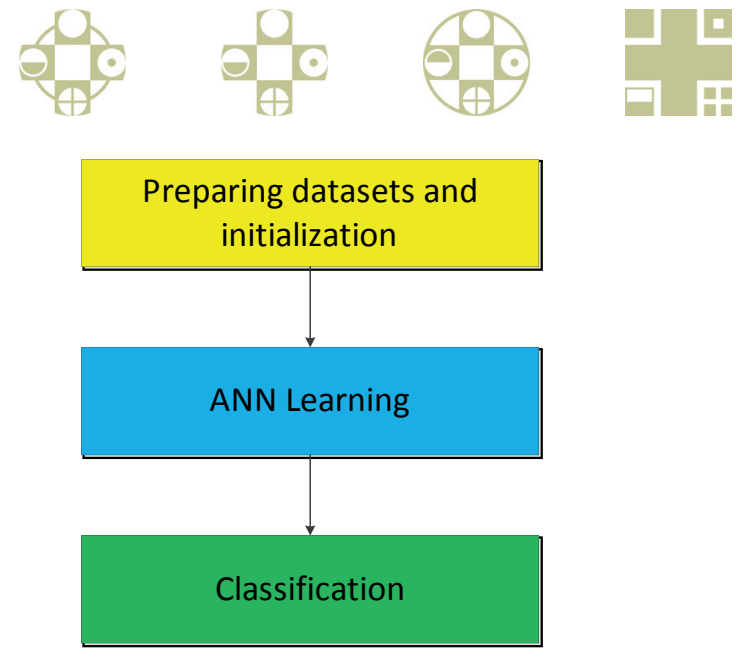

Figure 4. Block diagram of the proposed method

An input matrix is created from all PCG recordings. Each PCG record is represented as a column vector in the input matrix; thus, the number of columns in the input matrix is equal to the number of PCG recordings. The elements of these column vectors represent samples of a particular PCG signal.

For classification, a one-versus-all algorithm is used in which a single classifier per class is trained. For each class, prediction is performed by using a binary classifier and the result with the highest confidence score is chosen.

\section{PROPOSED METHOD}

A block diagram of proposed method is shown in Figure 4. The first step is to create training and test sets for each echo of the cross-validation method and to initialise all the ANN parameters. The second step is the back-propagation algorithm; it includes a calculation of the cost function and descent gradients and adjustment of the ANN weights. To adjust the weights, we try to minimise the cost function with the goal of minimising classification errors. The final step is classification using the one-versus-all algorithm.

\section{RESULTS}

While training the neural network, the database of phonocardiograms was divided into three classes : MVP, healthy and others (ill Figure 5). The analysis and selection of artificial neural network parameters suggested that 200 echoes was an optimal number for the proposed architec-

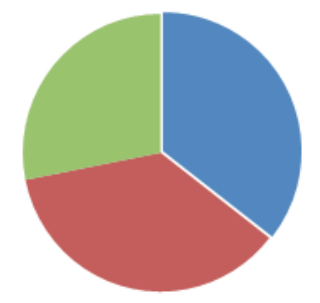

MVP healthy

others

Figure 5. Dataset 


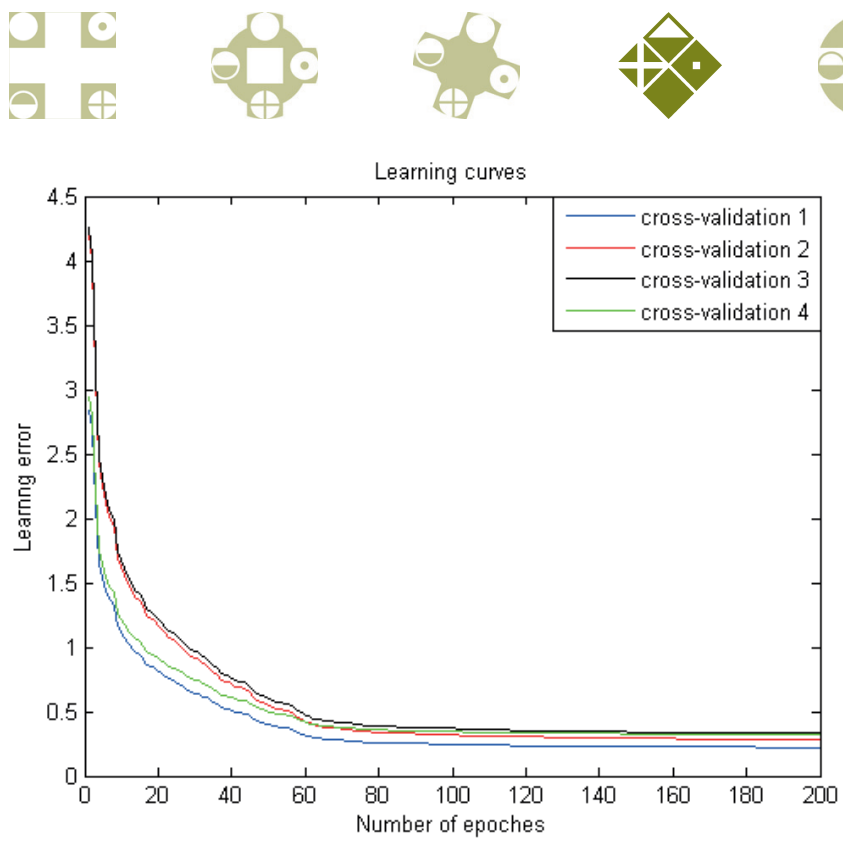

Figure 6. Learning curves for each step of cross-validation

ture. The enhanced number of iterations will not lead to a further reduction in training error. The presentation of the learning curve for each step in cross-validation is presented in Figure 6.

In each step of cross-validation, the accuracy of the algorithm was calculated by determining the percentage of accurately classified elements for all classes (Table 1). This factor was calculated by comparing the class elements obtained by the neural network with the classifications by a specialist doctor. A total accuracy of $71.2 \%$ in the class recognition was obtained by averaging all four steps of crossvalidation.

\begin{tabular}{|c|l|l|}
\hline \multirow{2}{*}{ Cross-validation 1 } & Recognise as 2 & 1 \\
\cline { 2 - 3 } & Recognise as 3 & 2 \\
\hline \multirow{2}{*}{ Cross-validation 2 } & Recognise as 2 & 0 \\
\cline { 2 - 3 } & Recognise as 3 & 3 \\
\hline \multirow{2}{*}{ Cross-validation 3 } & Recognise as 2 & 1 \\
\cline { 2 - 3 } & Recognise as 3 & 4 \\
\hline \multirow{2}{*}{ Cross-validation 4 } & Recognise as 2 & 2 \\
\cline { 2 - 3 } & Recognise as 3 & 2 \\
\hline
\end{tabular}

Table 1. False recognition of PMV in each cross-validation. The second column represents the class to which the PMV signal is classified. The third column shows the number of incorrectly classified PMV signals.

The analysis of the MVP class was especially interesting compared with that of the two other classes. For this research, the following parameters were analysed and these parameters were easily obtained using a confusion matrix. In each step of cross-validation, each of these parameters was calculated by using a confusion matrix (table 2). A confusion matrix was generated with the following values: TP (true positives) - number of input sets classified as MVP; FP (false positives) the number of input sets incorrectly classified as MVP; FN (false negatives) - number of MVP input sets that were not classified and TN

\begin{tabular}{|c|c|c|c|c|c|c|c|}
\hline \multirow{2}{*}{\multicolumn{2}{|c|}{ Cross-validation 1}} & \multicolumn{2}{|c|}{ Real } & \multirow{2}{*}{\multicolumn{2}{|c|}{ Cross-validation 2}} & \multicolumn{2}{|c|}{ Real } \\
\hline & & \multirow{2}{*}{$\frac{P}{9}$} & \multirow{2}{*}{$\frac{N}{4}$} & & & P & $\mathrm{N}$ \\
\hline \multirow{2}{*}{ Prediction } & $\mathrm{P}$ & & & \multirow{2}{*}{ Prediction } & $\mathrm{P}$ & 7 & 6 \\
\hline & $\mathrm{N}$ & 3 & 17 & & $\mathrm{~N}$ & 5 & 15 \\
\hline
\end{tabular}

(a)

\begin{tabular}{|l|l|l|l|}
\hline \multirow{2}{*}{ Cross-validation 3} & \multicolumn{2}{l|}{ Real } \\
\cline { 3 - 4 } & P & N \\
\hline \multirow{2}{*}{ Prediction } & P & 9 & 6 \\
\cline { 2 - 4 } & N & 3 & 15 \\
\hline
\end{tabular}

(v)

(b)

\begin{tabular}{|l|l|l|l|}
\hline \multicolumn{2}{|c|}{ Cross-validation 4 } & \multicolumn{2}{l|}{ Real } \\
\cline { 3 - 4 } \multicolumn{2}{|c|}{} & $\mathrm{P}$ & $\mathrm{N}$ \\
\hline \multirow{2}{*}{ Prediction } & $\mathrm{P}$ & 8 & 7 \\
\cline { 2 - 4 } & $\mathrm{N}$ & 4 & 14 \\
\hline
\end{tabular}

(g)

Table 2. Confusion matrix for each cross-validation: a) Cross-validation during using the last quarter of the set for the test; b) Cross-validation using the third quarter of the set for the test; v) Cross-validation using the second quarter of the set for the test; g) Cross-validation using the first quarter of the set for the test.

(true negatives) - the number of input sets that were not classified as MVP because they were not MVP.

For each class described above, the mean value obtained from four applications of cross-validation was used. Furthermore, the mean value of each parameter was calculated from each of these cross-validations. The accuracy of the MVP classification is given as follows :

$A=\frac{\sum_{1}^{4} \frac{T \Pi+T H}{T \Pi+T H+\Phi \Pi+\Phi H}}{4}=71.2 \%$

1. Level of classification error:

$E=\frac{\sum_{1}^{4} \frac{\Phi \Pi+\Phi H}{T \Pi+T H+\Phi \Pi+\Phi H}}{4}=28.8 \%$

2. Accuracy:

$\Pi=\frac{\sum_{1}^{4} \frac{T \Pi}{T \Pi+\Phi \Pi}}{4}=59.1 \%$

3. Recall:

$P=\frac{\sum_{1}^{4} \frac{T \Pi}{T \Pi+\Phi H}}{4}=68.75 \%$

4. Specificity:

$C=\frac{\sum_{1}^{4} \frac{T H}{T H+\Phi \Pi}}{4}=72.6 \%$

5. F-measure:

The same measures could be used for the other two classes; however, in this study, the classification of the MVP class was of primary importance. Hence, it is possible to determine which class of each classification was incorrectly identified as an MVP by the neural network. 


\section{DISCUSSION}

A PCG is a display of the heart sound signals and thus shows heart sounds and murmurs that can provide useful information to the physician by complementing cardiac auscultation. The basic methodology for distinguishing cardiac murmurs using the PCG is the same as that for interpreting murmurs from auscultation. However, the PCG provides additional information about the timing of cardiac phases and events. PCG provides a digital record that can be utilised to characterise the dynamic changes that are associated with therapy and the course of the disease. PCG complements auscultation.

The major clinical drawback of PCG is that it does not present information about the frequency (pitch) of heart sounds and their components. Frequency is one of the major characteristics that is considered when interpreting murmursin clinics . A PCG does not have the ability to differentiate separate multiple (folded) frequencies of various sounds and presents no information concerning dynamic changes in the energy (power) stored in the sound. Other deficiencies arguably include signal filtration effects (change in the visual representation due to filtration) and the presence of artefacts and noise that can visually mask weak sounds. Challenges in pinpointing the start and end points of certain sounds have been reported. The end point positions will also depend on the applied filter, which introduces additional uncertainty. Manual segmentation (separation of heart sound components) may be another problem as well.

PCG never achieved acceptance as a routine clinical investigative method but did find a valuable place in clinical investigations and research. However, the current newly developed "systems science" and signal processing computational technologies in combination with digital sound recording technologies, electronic recording stethoscopes, advanced new vibration sensors and finally, extraordinary computing power, now make it possible to completely revitalise old PCG-based approaches. The addition of the frequency (pitch) dimension to the PCG signal display provides further spectral information about the heart sounds.

Don Michael (10) illustrated the intrinsic properties of various heart lesions in his monograph "Auscultation of the Heart". Similar works have recently been reported by Balster et al. (11) and Nopponen and Lukkarinen (12, 13). Tovar-Corona et al. $(14,15)$, DeGroff et al. (16), Tuchinda and Thompson $(17,18)$ utilised a wavelet-based transform to obtain time-varying scalogram maps. The spectrogram offers additional insight into time-dependent changes in murmur frequency. Donnerstein (19) correlated the frequency characteristics in a spectrogram with the Doppler echo velocity. Tavel \& Katz $(20,21)$ reported a method for clinical differentiation of aortic stenosis from an innocent murmur using spectrogram measurements. Finally, Tavel (22) indicated great promise for this approach in clinical diagnosis.
Unfortunately, the methods described in other papers $(17,20)$ use various forms of the short-term fast Fourier transform (STFT) to obtain the instantaneous frequency characteristics of signals and all these methods are subject to the "quantum uncertainty" theorem, which states that a signal and its Fourier transform cannot both be concentrated (23) and that frequency and time cannot both be determined to arbitrary precision $(24,25)$. The resulting outcome of this drawback is a non-unique, low-fidelity image, which changes depending on the frequency resolution $(26,27)$. Additionally, heart sounds are nonlinear, non-sinusoidal and exponential signals and signal processing research (28) has demonstrated that the Fourier transform is not a mathematically appropriate method to study such signals.

Tuchinda and Thompson (29), Tovar-Corona et al. (14, 15) and DeGroff et al. (16) utilised a continuous wavelet based transformation (CWT) to develop maps that resemble spectrograms and present the wavelet scale variation in time (scalograms). The CWT approach is not as well established as the traditional spectrogram approach in clinical studies (17), but the use of CWT and is presently increasing. Unlike STFT spectrograms, for CWT, the time and frequency resolution is non-uniform in the entire time-frequency domain (30). At high frequencies, there is good time resolution and bad frequency resolution. At low frequencies, the frequency resolution is better and the time resolution is worse. Thus, this results in smearing of the time-frequency representation of the signal in time at low frequencies. The speed of wavelet transform computations and the improved resolution over the STFT are the primary reasons that the wavelet transforms have become a popular analysis tool (22). The graphical results presented by Tuchinda and Thompson (29) also fail to provide sufficient qualitative resolution and have a strong visual "skewness" compared with traditional spectrograms.

There are numerous recent publications on the subject of the digital recording and analysis of heart sounds. Green et al. (31) discuss optimal methods of recording heart murmur findings using SNOMED templates, DeGroff et al. (16) suggest a potential for computerised frequency analysis to improve further the accuracy of murmur assessment and Nigam et al. (32) introduced new methods of segmenting heart sound signals. Finley et al. (33) demonstrated the diagnostic quality of email digital recordings of children's heart sounds and that these recordings allow accurate distinction between normal and pathological murmurs in $>90 \%$ of cases. Kudriavtsev et al. (34) demonstrated that Still's murmurs have a narrow spectral bandwidth, a significant feature that can differentiate them from abnormal murmurs.

Clinical interest in spectrographic representations of heart sounds is clearly increasing. However, existing signal processing methods lack accuracy and resolution. Unlike other short-term Fourier transform-based approaches (19) and Gabor's transformation (22) which provides an approximation of the instantaneous energy distribution of a signal, the Wigner-Ville distribution $(35,36)$ has been derived to 
compute the signal energy at each time instant, precisely utilising knowledge of the entire signal to compute the timefrequency properties for each moment in time.

The biomedical research community has shown more interest in the detection and classification of cardiac sounds via phonocardiography and auscultation in cardiac diagnosis. Different support-decision systems are developed using phonocardiography and automatic classifiers (37). An ANN-based classifier can be used for heart sound analysis, where different approaches may precede the classification process, such as the previously described wavelet representation (37). The phonocardiograms (38) were subjected to a fast Fourier transform to extract the energy spectrum in the frequency domain to detect heart murmurs in children. The processed signals were used to develop statistical classifiers and a classifier based on ANN. The ability to distinguish pathological and normal heart murmurs may provide valuable information about a potential diagnosis. Another example of diagnosis-oriented classification is the method proposed by Reed et al. for the classification of heart acoustics signals based on a least square support vector machine (LSSVM) using a wavelet-based feature set (38). In this paper, an ANN-based method for determining the diagnosis for a specific condition, mitral valve prolapse, is proposed .

This paper proposed an ANN-based method for automatic detection of mitral valve prolapse. The selected method uses MLP with a back-propagation batch gradient descent learning algorithm. The proposed ANN-based architecture showed $71.2 \%$ accuracy. Here, we use 200 epochs for learning and we conclude from experiments that the error does not change when more epochs are used for learning.

The adopted model of artificial neural networks includes the results using two successive layers of a perception neural networkand and has three layers: input, hidden and output. The input layer has 64033 neurons; the hidden layer has 95 neurons; and the output layer has 2 neurons . The network was trained using a learning algorithm using the backward and batch gradient algorithms. The cross-validation one against all (one- versus- all) algorithms were used for validation and classification, respectively . The training and validation of the neural network used two different data sets. Methods such as the confusion matrix mall together with the various statistical values that can be derived from it were used to evaluate the network.

Compared with other works, our method is different in that it does not use data preprocessing. The data were obtained directly from the electronic stethoscope, without selection of the most suitable cardiac cycle by an expert. The data include the full eight-second recordings Electrocardiograms that were recorded in parallel were not available but are necessary for successful segmentation, as mentioned in the presented work; therefore, it was not possible to perform segmentation prior to the analysis . Another approach to segmentation that has been described involves the use of Shannon's energies, but this method utilises a carefully selected cycle or just one cardiac cycle. Although the accuracy and specificity of our approach is less than that of the described work, we consider our method to be more objective because it does not require an expert to select quality cycles. For the same reason, that method only considers changes in the appearance of the cycle and more robust murmurs and PMV is not required to occur in every cardiac cycle. This technique differs from our approach to the classification of a specific disorder that can be detected by PCG (PMV) and the classification of other pathological and healthy signals, as in most of the described work. Again, we would note that the results are validated in a completely new set of data that the network had not previously used.

The present analysis of phonocardiographic signals usually includes electrocardiography as a reference method. Our method has shown that it is possible to create a system that would be based only on PCG.

Further research should be able to increase the accuracy and specificity of the method described. The proposed method is signal based. It does not involve calculating features or preprocessing of signals. To improve the classification ANN should be supported by specific features. Several solutions have been proposed so far and the wavelet transform is considered to be a promising tool, which can result in localisation of the click murmur syndrome in phonocardiograms.

\section{CONCLUSION}

The obtained result can be considered a useful tool for clinical support in the initial examination of phonocardiograms and may reveal mitral valve prolapse in children by phonocardiography.

\section{ACKNOWLEDGMENTS}

This work is supported by the Grant No. 175043 from the Ministry of Science and Technical Development of the Republic of Serbia.

\section{CONFLICT OF INTERESTS}

All the authors of the present paper disclose that they have no actual or potential conflict of interests, including any financial, personal or other relationships with other people or organisations.

\section{REFERENCES:}

1. Ostojić M, Kanjuh V, Beleslin B. Kardiologija. Beograd: Zavod za udzbenike i nastavna sredstva, 2011.

2. Završnik J, Malčić, I. Mitral valve prolapse and mitral valve prolapse sindrome in children / Pedijatrijska kardiologija, odabrana poglavlja - 2. dio / Ivan Malčić, (ed). Zagreb: Medicinska naklada, 2003. 
3. Rajakumar K, Weisse M, Rosas A, et al. Comparative study of clinical evaluation of heart murmurs by general pediatricians and pediatric cardiologists. Clin Pediatr 1999; 38: 511-18.

4. Becket MC, Nowalk A, Hofkosh D, Zuberbuhler JR, Law YM. Comparison of Two Educational Interventions on Pediatric Resident Auscultation Skills. Pediatrics 2004; 113: 1331-35.

5. Sztajzelag JM, Kossovsky MP, Lerchab R, Vuilleac C, Sarasind FP. Accuracy of cardiac auscultation in the era of Doppler-echocardiography: A comparison between cardiologists and internists. Cardiology 2008; 138: 308-10.

6. Tavel ME. Cardiac auscultation: a glorious past: and it does have a future. Circulation 2006; 113:1255-59.

7. Pelech N. The physiology of cardiac auscultation. Pediatr Clin North Am 2004; 51: 1515-35.

8. Haykin S. Neural Network: A Comprehensive Foundation. Pearson, 1999.

9. Hu YH, Hwang J. Handbook of Neural Network Signal Processing. CRC Press, 2001.

10. Don Michael TA. Auscultation of the Heart: A Cardiophonetic Approach. McGraw Hill 1998; 392.

11. Balster DA, Chan DP, Rowland DG, Allen HD. Digital acoustic analysis of precordial innocent versus ventricular septal defect murmurs in children. Am J Cardiol 1997; 79: 1552-55.

12. Noponen AL, Lukkarinen S, Angela A, Sikio K, Sepponen R. How to recognise innocent vibratory murmur. Comp in Cardiol 2000; 27: 561-64.

13. Noponen AL. 4th Congress on Pediatric Cardiology. Poster Presentation 2005.

14. Tovar-Corona B, Hind MD, Torry JN, Vincent R. Effects of respiration on heart sounds using time-frequency analysis. Comp in Cardiol 2001; 457-60.

15. Tovar-Corona B, Torry JN. Time-frequency representation of systolic murmurs using wavelets. Comput in Cardiol 1998; 601-04.

16. DeGroff CG, Bhatikar S, Herzburg J, Shandas R, VladesCruz L, Mahajan RL. Artificial neural network-based method of screening heart murmurs in children. Circulation 2001; 103: 2711-16.

17. Tuchinda C, Thompson WR. Cardiac auscultatory recording database: delivering heart sounds through the internet. Proc AMIA Symp 2001; 716-20.

18. Hayek CS, Thompson WR. Wavelet processing of systolic murmurs to assist with clinical diagnosis of heart disease. Biomed Instrum Technol (Biomedical instrumentation \& technology/Association for the Advancement of Medical Instrumentation) 2003; 37: 263-70.

19. Donnerstein R, Thomsen VV. Hemodynamic and anatomic factors affecting the frequency content of Still's innocent murmur. Am J Cardiol 1994; 74: 508-10.
20. Tavel ME, Katz H. Usefulness of a new sound spectral averaging technique to distinguish an innocent systolic murmur from that of aortic stenosis. Am J Cardiol 2005; 95: 902-04.

21. Kim D, Tavel ME. Assessment of severity of aortic stenosis through time-frequency analysis of murmur. Chest 2003; 124: 1638-44.

22. Tavel ME. Cardiac auscultation: a glorious past: and it does have a future. Circulation 2006; 113: 1255-59.

23. Lang CW, Forinash K. Time-frequency analysis with the continuos wavelet transform.Am J Phys 1998; 66: 794-97.

24. Wigner E. On the quantum correction for thermodynamic equilibrium. Phys Rev 1932; 40: 749-59.

25. Messiah A. Quantum mechanics. North Holland, Amsterdam 1970; 1:50.

26. Rein S, Reisslein M. Identifying the classical music composition of an unknown performance with wavelet dispersion vector neural nets (extended version). Information Sciences 2006; 176: 1629-55.

27. Signal processing toolbox for use with Matlab, Version 5 Mathworks 2002; 1-800.

28. Reed TR, Reed NE, Fritzson P. Heart Sound analysis for symptom detection and computer-aided diagnosis. Sim Mod Practice and Theory 2004; 12: 129-46.

29. Tuchinda C, Thompson WR. Cardiac auscultatory recording database: delivering heart sounds through the internet. Proc AMIA Symp 2001; 716-20.

30. Qian S, Dapang CD. Joint time-frequency analysis: method and applications. Prentice Hall, NJ 1996; 78-9.

31. Green JM, Wilcke JR, Abbott J, Rees LP. Development and evaluation of methods for structured recording of heart murmur findings using SNOMED-CT post-coordination. J Am Med Inform Assoc 2006; 13:321-33.

32. Nigam V, Priemer R. Accessing heart dynamics to estimate durations of heart sounds. Physiol Meas 2005; 26:1005-18.

33. Finley P, Warren AE, Sharratt GP, Amit M. Assessing children's heart sounds at a distance with digital recordings. Pediatrics 2006; 118: 2322-25.

34. Kudriavtsev VV, Kaelber D, Lazbin M, Polyshchuk VV, Roy DL. New tool to identify Still's murmurs. Pediatric Academic Societies Annual Meeting 2006; April 29-May 2.

35. Wigner E. On the quantum correction for thermodynamic equilibrium. Phys Rev 1932; 40: 749-59.

36 . Ville J. Theorie et applications de la notion de signal analytique. Cables et Transmission 1948; 1: 61-74.

37. Bhatikar SR, DeGroff C and Mahajan RL. A classifier based on the artificial neural network approach for cardiologic auscultation in pediatrics. Artificial Intelligence in Medicine 2005; 33: 251-60.

38. Ari S, Hembram K, Saha G. Detection of cardiac abnormality from PCG signal using LMS based least square SVM classifier, Expert Systems with Applications: An International Journal 2010; 37: 8019-26. 